Ind. Health, 1974, 12, $75^{\jmath}$.

\title{
A STUDY ON URBAN PARTICULATE AIR POLLUTANTS BY THIN METAL FILM METHOD
}

\author{
Hiroyuki SAKABE, Katsunori HOMMA and Tetsuo ISHIDA \\ National Institute of Industrial Health, Kizuki-Sumiyoshi, Nakahara-ku, Kawasaki \\ and \\ Kawasaki Municipal Research Institute for Environment Protection, \\ Tajimacho, Kawasaki-ku, Kawasaki \\ (Received January 18, 1974)
}

\begin{abstract}
Particulate pollutants in urban air were collected on collodion membrane and thin metal film, and observed electronmicroscopically. Particles which took a jellied or greasy appearance and evaporated after exposure to electron beam on collodion membrane were noticed. On metal film, these jellied particles showed various appearances different from those on collodion membrane in consequence of an interaction between some components of particles and metal.

Strong corrosiveness of jellied particles seen in summer may have some relation to the irritability of air pollutants to mucous membrane by air pollution.
\end{abstract}

In order to see particulate matters in urban air clearly, we have to use electronmicroscope as they are very small. Electronmicrograph of these particles collected on ordinary membrane offers an information on morphological characteristics of each particle, but it does not offer any information on its chemical nature or activity. We devised a thin metal film method in $1964^{1,2)}$ to get further information about particles. This paper describes the results of some investigations on particulate pollutants by this method.

\section{Preparation of Thin Metal Film and Collection of Sample}

Collodion coated specimen grid was placed on a cover glass and its surface was covered with fume evaporated from metal heated in tungsten wire coil in vacuum evaporator. The thickness of this film formed by metal fume deposited on collodion membrane was assumed to be 50 to $100 \AA$. As for metal, copper was used usually, but silver, iron, zinc and other metals may be used according to the purpose of study.

Particles in the air were collected on this thin metal film by impaction using Owens type dust collector in which humidifying part was removed. Density of collected particles was controlled by pumping frequency. Collected particles were examined electronmicroscopically.

The air was sampled at the top of the building of the National Institute of 


\section{H. SAKABE, K. HOMMA AND T. ISHIDA}

Industrial Health, which is located in Kawasaki City lying in the middle of a megalopolis consisting of Tokyo, Kawasaki and Yokohama where many heavy industries, chemical industries and airport are concentrated along Tokyo Bay. (Fig. 1)

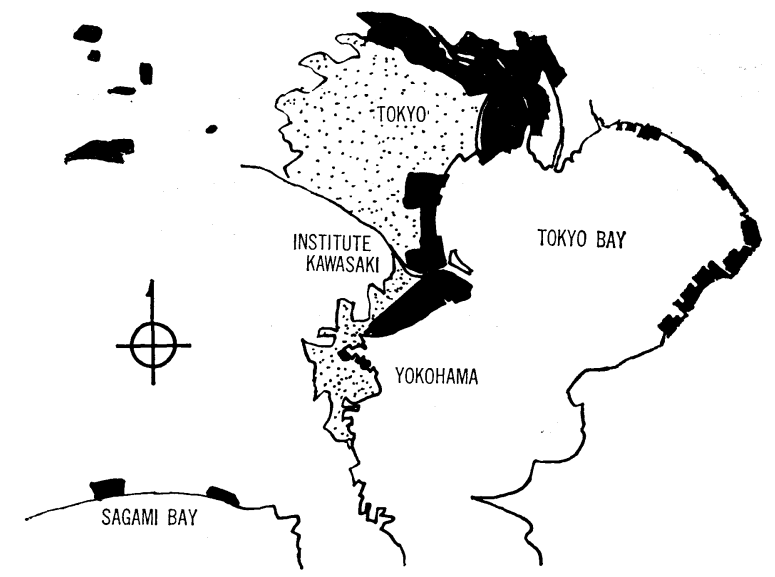

Fig. 1. Location of the National Institute of Industrial Health. Black part shows industrial area.

\section{RESULTS}

There was a noticeable difference between particulate air pollutants sampled when the wind blew from the inland and from the sea. In the latter case, it was assumed that the pollutants from an industrial area reached the Institute. Difference between properties of pollutants in winter and summer was also noticed.

\section{Particulate matter in winter}

Particles shown in Fig. 2 were collected on collodion membrane on 8 November 1971. It blew from the sea. Picture on the right side shows particles after strong electron beam exposure for about half a minute. Particulate pollutants consist of small solid particles and particles which look like jelly or greasy. The latter particles lose opacity after strong electron beam exposure. Fig. 3 shows the particles collected on copper film just after the previous sample was collected. Particles show a quite different figure from those on collodion membrane. Very small particles which are assumed to be carbon particles and jellied particles are seen. Size of jellied particles is various, and some of particles show different opacity zones arranged in homocentric or heterocentric. Almost all jellied particles show holes formed by the disappearance of copper insice them. This hole formation is assumed to be due to an interaction between some components of particles and copper resulting in the dissolution of copper fume. Such a figure of particles on copper film was seen frequently in winter. A similar pattern of particles was already obtained in winter of 1964 in Yokkaichi city ${ }^{1)}$ as seen in Fig. 4, though in 


\section{PARTICULATE AIR POLLUTANTS ON THIN METAL FILM}

this case some particles formed holes in them and some halos around them.

\section{Particulate pollutant in summer}

Fig. 5 shows the pollutants collected on collodion membrane on 31 May 1972. It blew from the inland. Particles are very fine ones which seem to be carbon and their aggregates. There is no difference between before and after strong electron beam exposure.

Fig. 6 shows particles collected on copper film on the same day. A very few solid particles formed halos around them. This is a typical pattern of particles when it blew from the inland in summer. However, when it blew from the sea, particles took a quite different appearance from this. Fig. 7 shows the particles on collodion membrane on 17 June 1972. It blew from the sea. Almost all particles show jellied appearance and their size is various. After an exposure to electron beam, jellied parts evaporate leaving very small solid particles. Fig. 8 shows the similar particles collected on copper film on the same day. Most of the particles do not attack copper though only a few form holes. Fig. 9 shows the particles on collodion membrane on 23 July 1971. Particles are jellied and evaporate after an exposure to electron beam. On copper film, all these jellied particles form halos around them as seen in Fig. 10.

An unusual pattern was seen on 11 June 1972 as seen in Figs. 11, 12 and 13. Almost all particles are jellied and their size and opacity are various. Jellied parts evaporate after an exposure to electron beam. Fig. 12 shows the particles on copper film. All jellied particles disappeared leaving round holes in copper film, and some holes contain very small solid particles in them. Fig. 13 shows these holes by high magnification. Solid particles take very similar figures. These small particles are assumed to be a chemical compound produced by chemical interaction between the pollutants and copper.

\section{Conclusion}

As far as we have studied, particulate air pollutants in Kawasaki city may be primarily divided into two sorts of particles: one is solid particle and the other jellied one. Almost all of solid particles seem to be carbon or carbonaceous substances. Some of these solid particles seem to adsorb some substances which attack copper film. Jellied particles on collodion membrane take round or oval shape, show a rather homogeneous opacity and lose their composition by strong electron beam exposure.

Jellied particles on copper film may be classified into the following four types.

1) Jellied particles which do not attack copper membrane,

2) Jellied particles which attack copper and form holes inside them,

3) Jellied particles which attack copper and form halo around them,

4) Jellied particles which attack copper and disappear after leaving hole in the 


\section{H. SAKABE, K. HOMMA AND T. ISHIDA}

copper film.

\section{DisCUSSION}

It is interesting that what kinds of chemical substances compose the jellied particles and what kinds of chemical components of particles form hole or halo after reacting on copper membrane.

The effects of various inorganic acid and salts on thin copper film under enough humidity are shown in Table 1. Sulphuric acid, nitric acid, and some of sulfite, sulfate and nitrate form hole on copper membrane. It seems very probable that jellied particles in summer of 1972 was composed of inorganic acids or their salts as they were soluble in water.

Table 1. Hole formation of various inorganic acids and salts on copper film under enough humidity.

$\bigcirc$ : hole formation

$X$ : no hole formation

\begin{tabular}{|c|c|c|}
\hline Substance & & $\begin{array}{l}\text { Hole 'formation } \\
\text { in } \mathrm{Cu} \text { film }\end{array}$ \\
\hline Sulphuric acid & $\mathrm{H}_{2} \mathrm{SO}_{4}$ & 0 \\
\hline Nitric acid & $\mathrm{HNO}_{3}$ & $\bigcirc$ \\
\hline Ammonium sulphite & $\left(\mathrm{NH}_{4}\right)_{2} \mathrm{SO}_{3}$ & 0 \\
\hline Sodium sulphite & $\mathrm{Na}_{2} \mathrm{SO}_{3}$ & O \\
\hline Ammonium sulfate & $\left(\mathrm{NH}_{4}\right)_{2} \mathrm{SO}_{4}$ & 0 \\
\hline Sodium sulfate & $\mathrm{Na}_{2} \mathrm{SO}_{4}$ & $x$ \\
\hline Potassium sulfate & $\mathrm{K}_{2} \mathrm{SO}_{4}$ & $x$ \\
\hline Sodium hydrogen sulfate & $\mathrm{NaHSO}_{4}$ & 0 \\
\hline Potassium hydrogen sulfate & $\mathrm{KHSO}_{4}$ & 0 \\
\hline Iron (II) ammonium sulfate & $\left(\mathrm{NH}_{4}\right)_{2} \mathrm{SO}_{4} \mathrm{FeSO}_{4}$ & $x$ \\
\hline Iron (III) ammonium sulfate & $\left(\mathrm{NH}_{4}\right)_{2} \mathrm{SO}_{4} \mathrm{Fe}_{2}\left(\mathrm{SO}_{4}\right)_{3}$ & O \\
\hline Sodium nitrite & $\mathrm{NaNO}_{2}$ & $x$ \\
\hline Ammonium nitrate & $\mathrm{NH}_{4} \mathrm{NO}_{3}$ & O \\
\hline Sodium nitrate & $\mathrm{NaNO}_{3}$ & $x$ \\
\hline Potassium nitrate & $\mathrm{KNO}_{3}$ & $x$ \\
\hline Zinc nitrate & $\mathrm{Zn}\left(\mathrm{NO}_{3}\right)_{2}$ & 0 \\
\hline Copper nitrate & $\mathrm{Cu}\left(\mathrm{NO}_{3}\right)_{2}$ & O \\
\hline Lead nitrate & $\mathrm{Pb}\left(\mathrm{NO}_{3}\right)_{2}$ & $x$ \\
\hline Iron (III) nitrate & $\mathrm{Fe}\left(\mathrm{NO}_{3}\right)_{3}$ & 0 \\
\hline
\end{tabular}

Jellied particles which are strongly corrosive to copper film are assumed to be also irritative to human mucous membrane. It is noteworthy that more than one hundred persons in Kawasaki city complained of irritation of eyes and throat on 11 June 1972 when particulate pollutants were so corrosive to copper as seen in Figs. 12 and 13, though correlation between epidemiological survey on health effects of air pollution and electronmicroscopic study of particulate pollutants has not yet been studied. 
PARTICULATE AIR POLLUTANTS ON THIN METAL FILM

\section{REFERENCES}

1) Sakabe, H. (1964). Proc. Roy. Soc. Med., 57, 1005.

2) Homma, K. and Sakabe, H. (1968). Ind. Health, 6, 80. 
PARTICULATE AIR POLLUTANS ON THIN METAL FILM

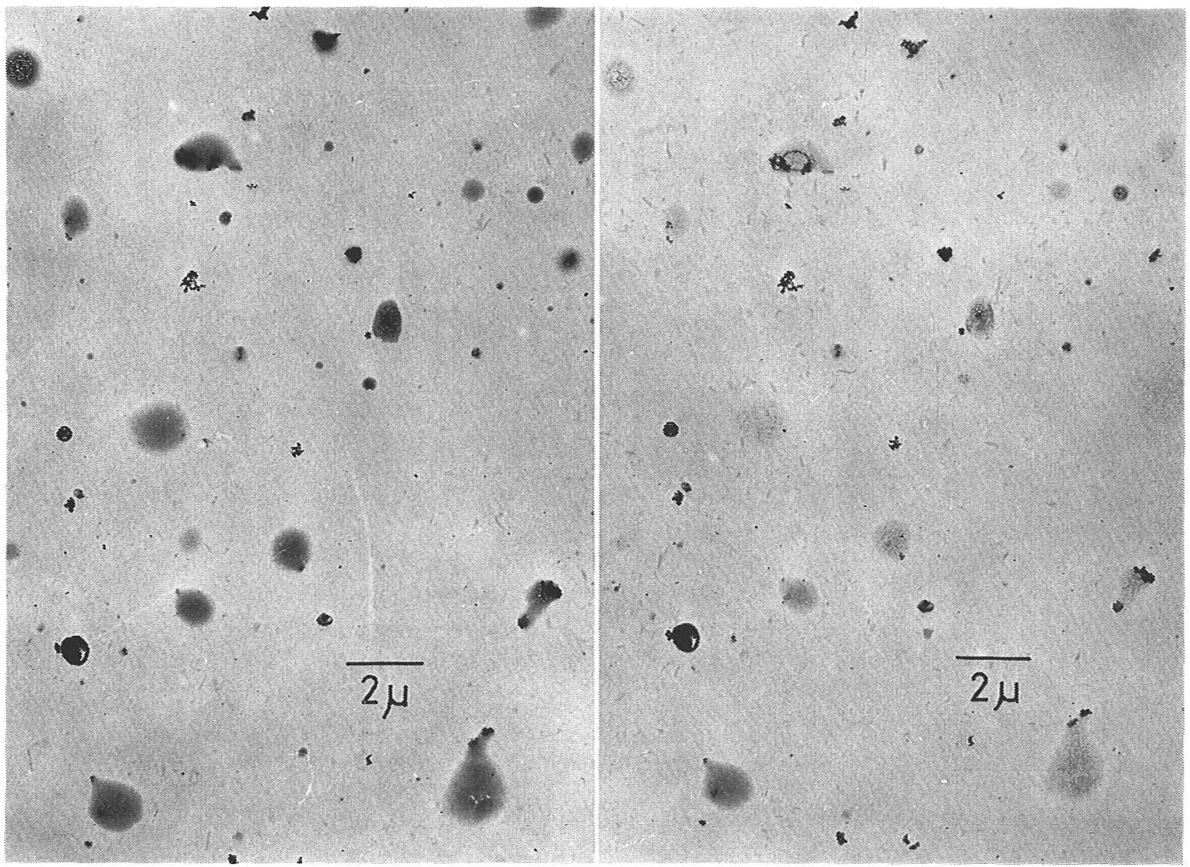

Fig. 2. Particles collected on collodion membrane on 8 November 1971. Before (left) and after (right) an exposure to electron beam.

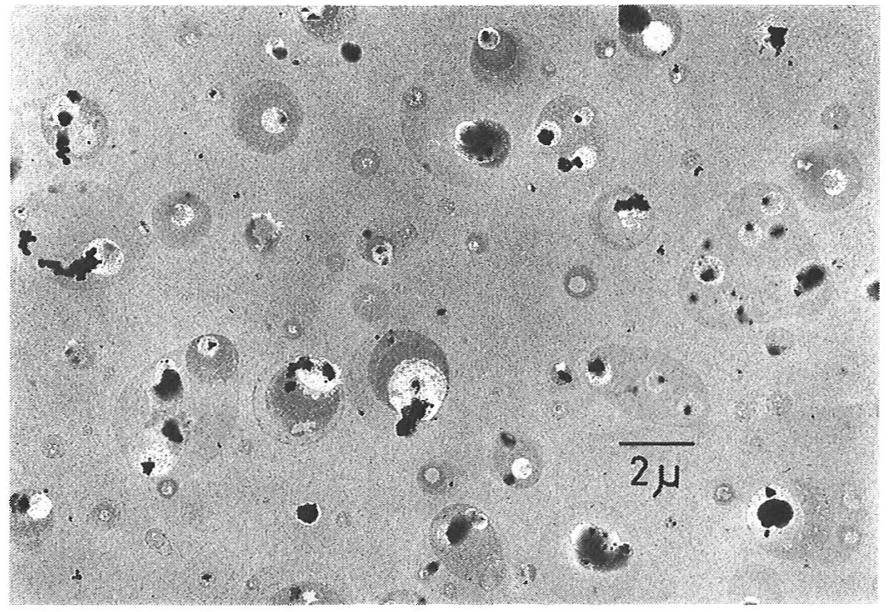

Fig. 3. Particles collected on copper film on 8 November 1971. 


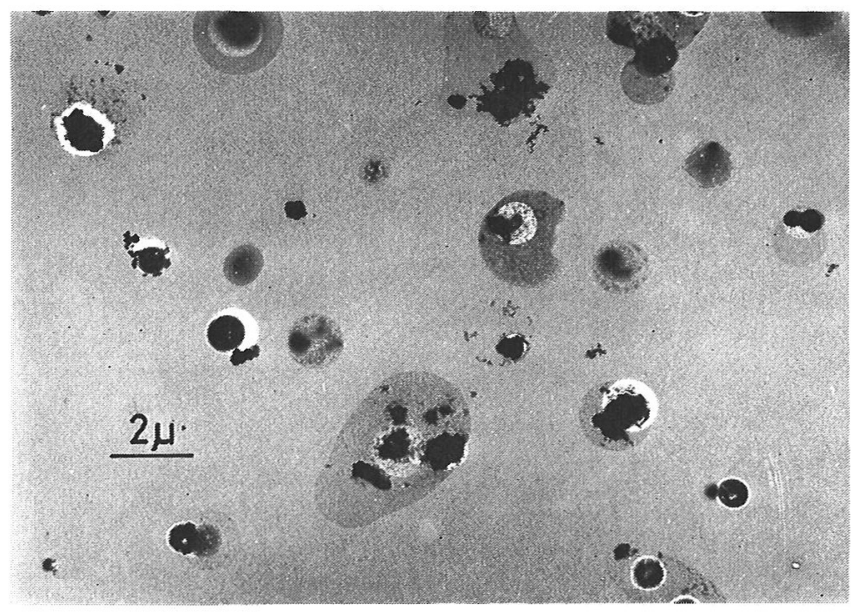

Fig. 4. Particles collected on copper film in February 1964 in Yokkaichi city.

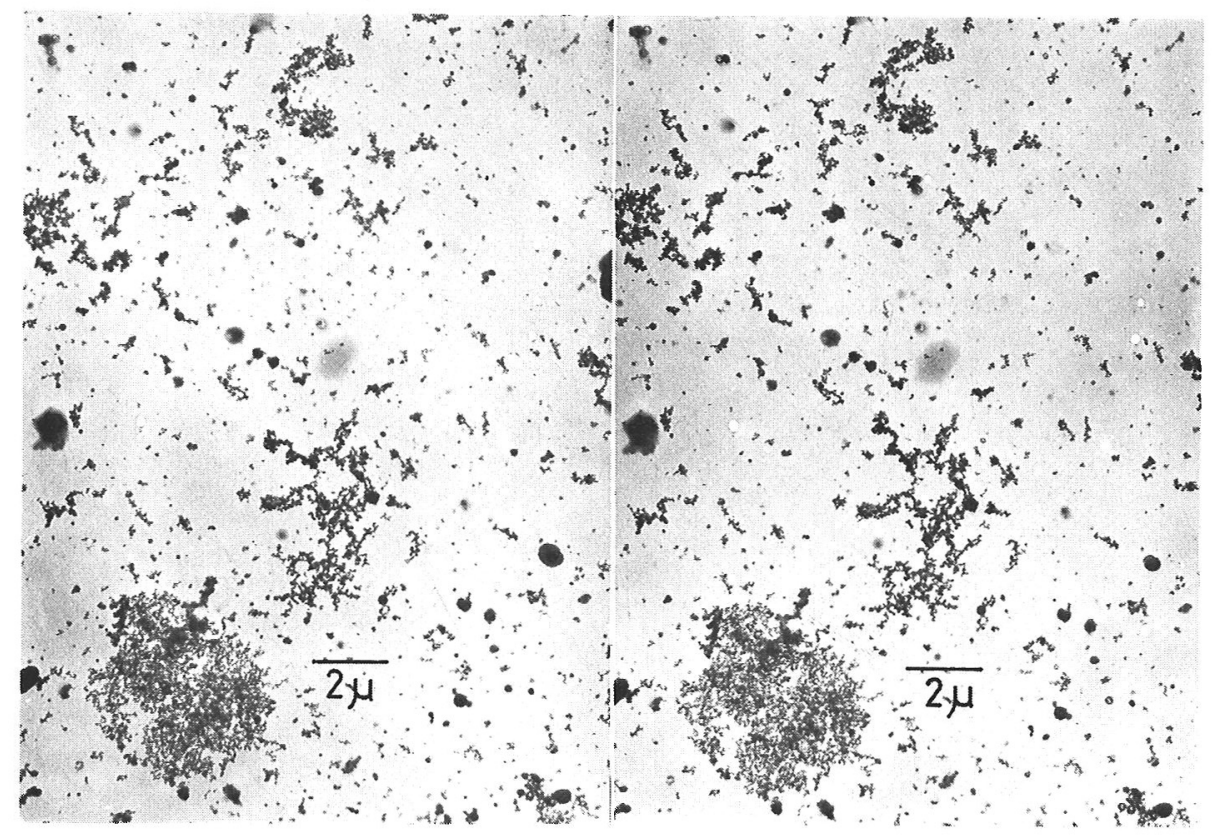

Fig. 5. Particles collected on collodion membrane on 31 May 1972. Before (left) and after (right) an exposure to electron beam. 


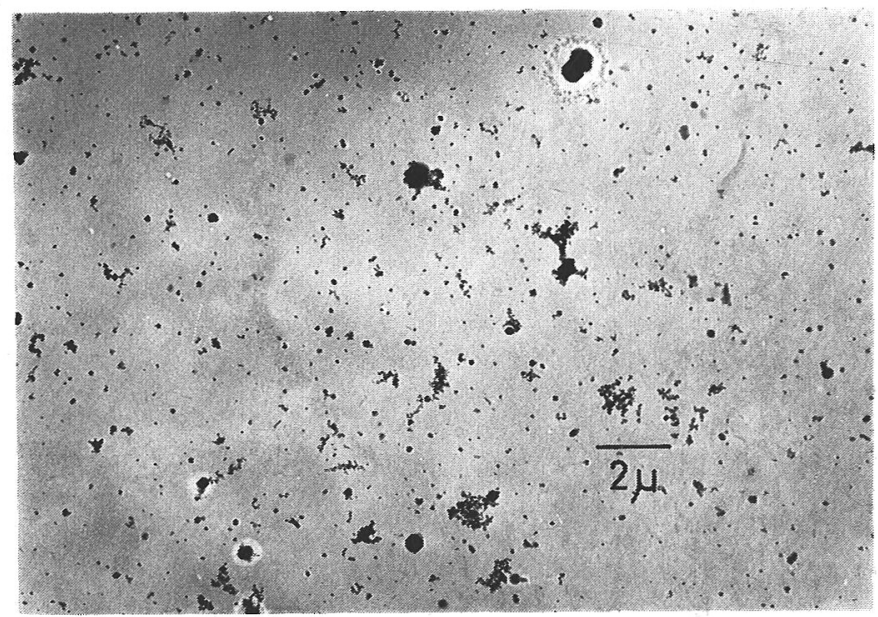

Fig. 6. Particles collected on copper membrane on 31 May 1972.

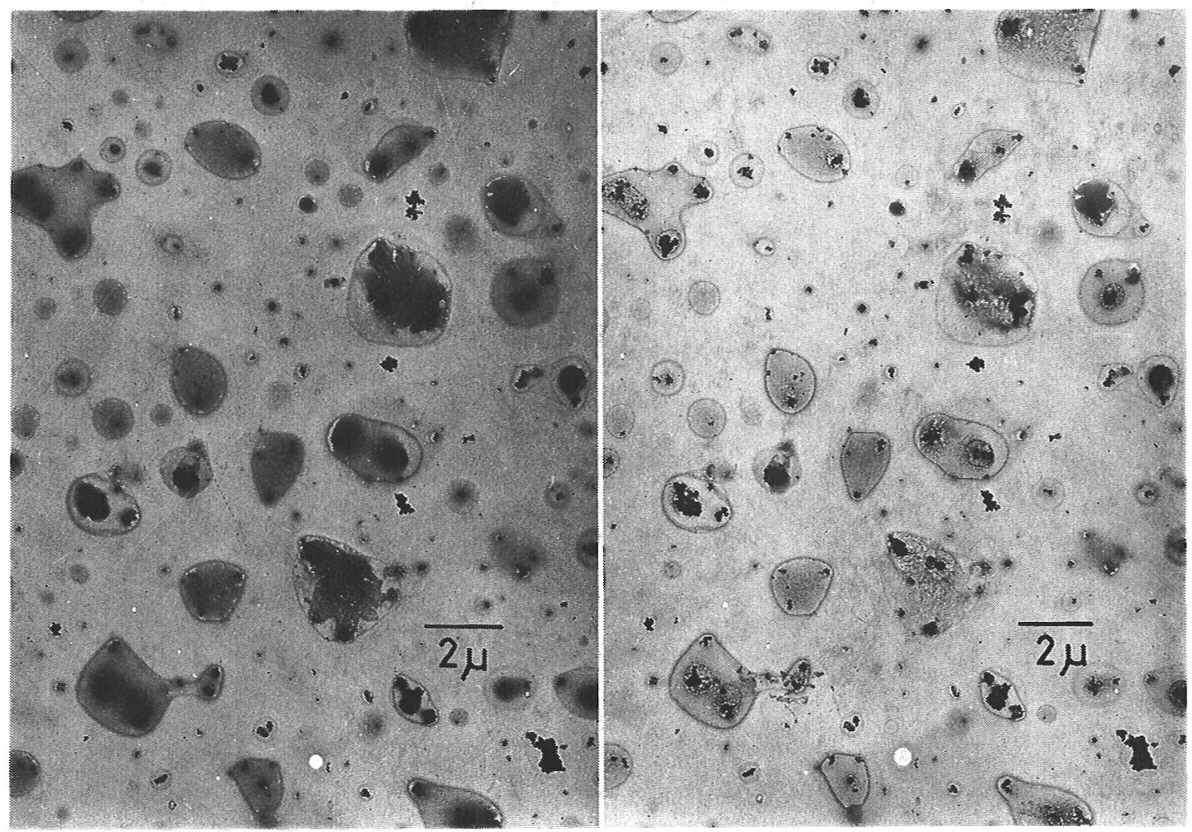

Fig. 7. Particles collected on collodion membrane on 17 June 1972.

Before (left) and after (right) an exposure to electron beam. 
H. SAKABE, K. HOMMA AND T. ISHIDA

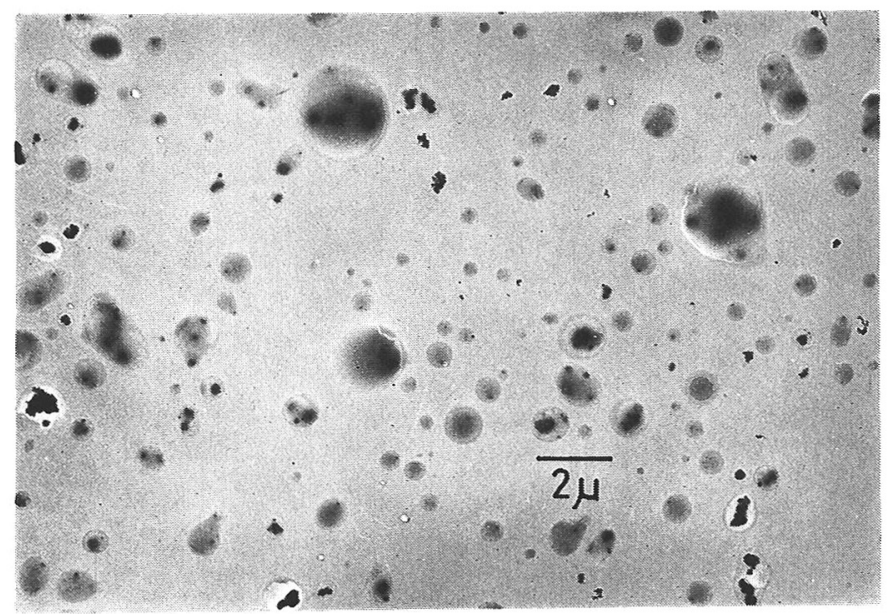

Fig. 8. Particles collected on copper membrane on 17 June 1972.

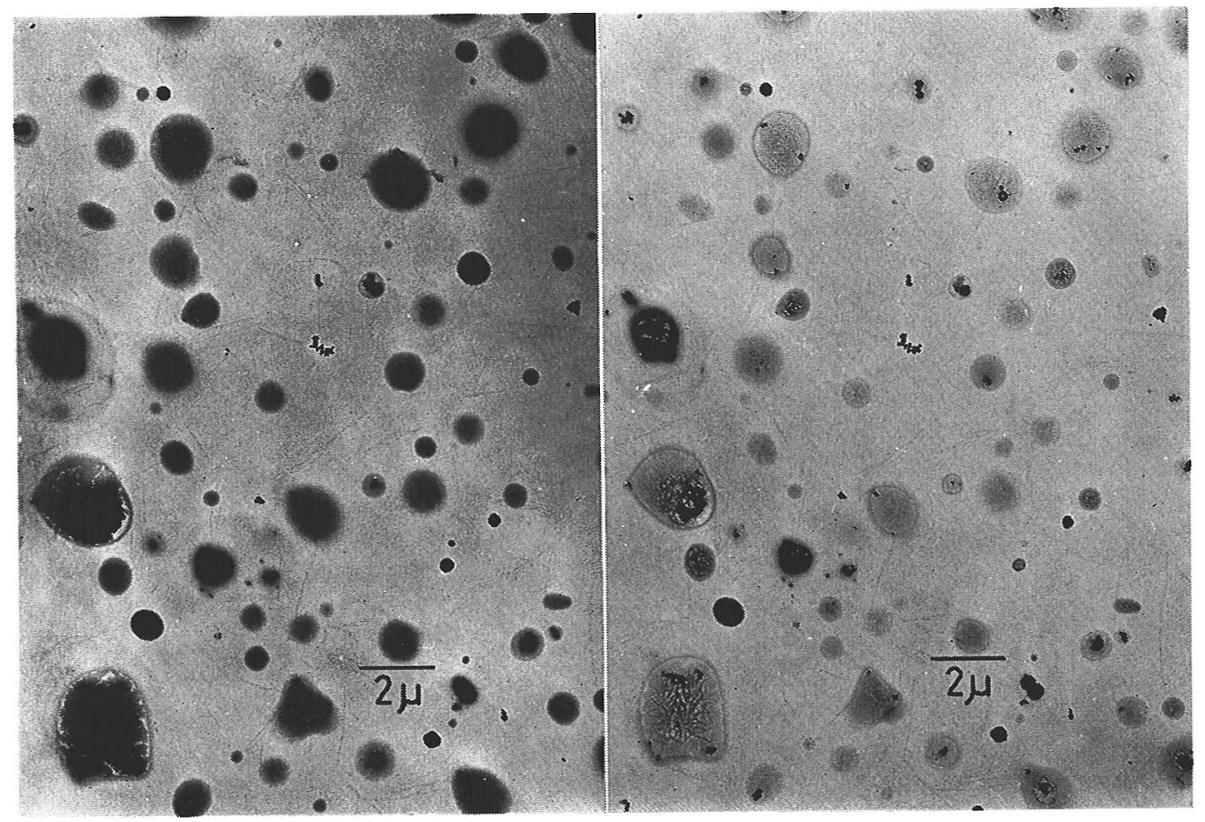

Fig. 9. Particles collected on collodion membrane on 23 July 1971. Before (left) and after (right) an exposure to electron beam. 


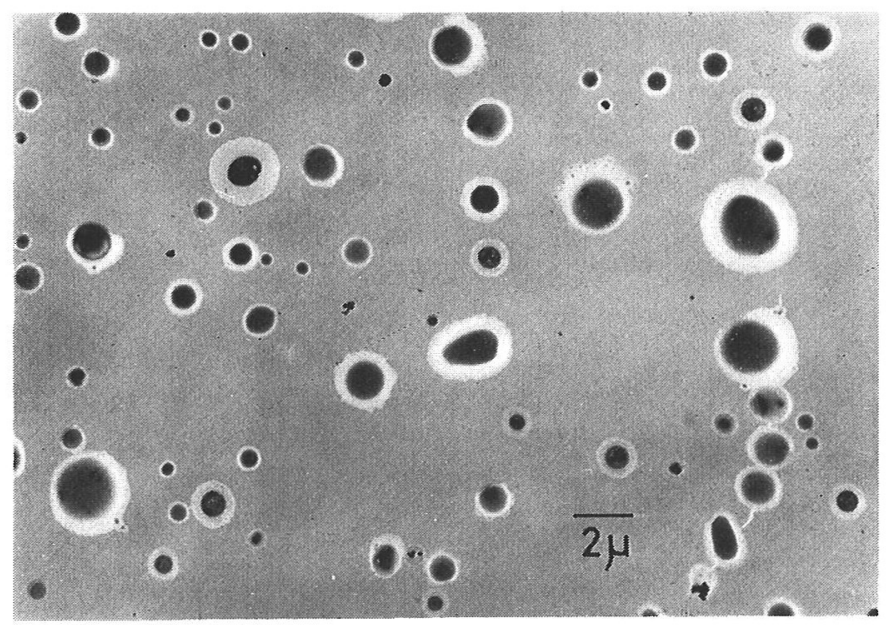

Fig. 10. Particles collected on copper film on 23 July 1971.

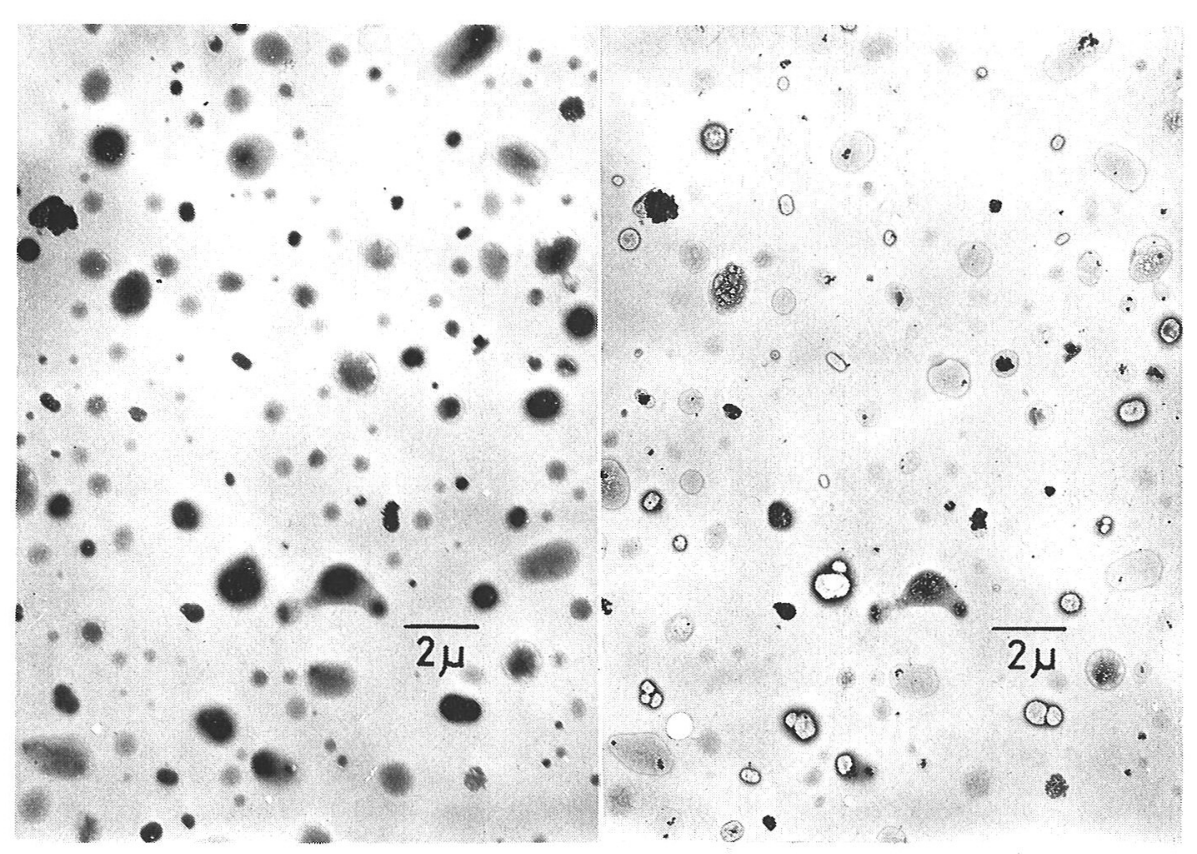

Fig. 11. Particles collected on collodion membrane on 11 June 1972. Before (left) and after (right) an exposure to electron beam. 
H. SAKABE, K. HOMMA AND T. ISHIDA

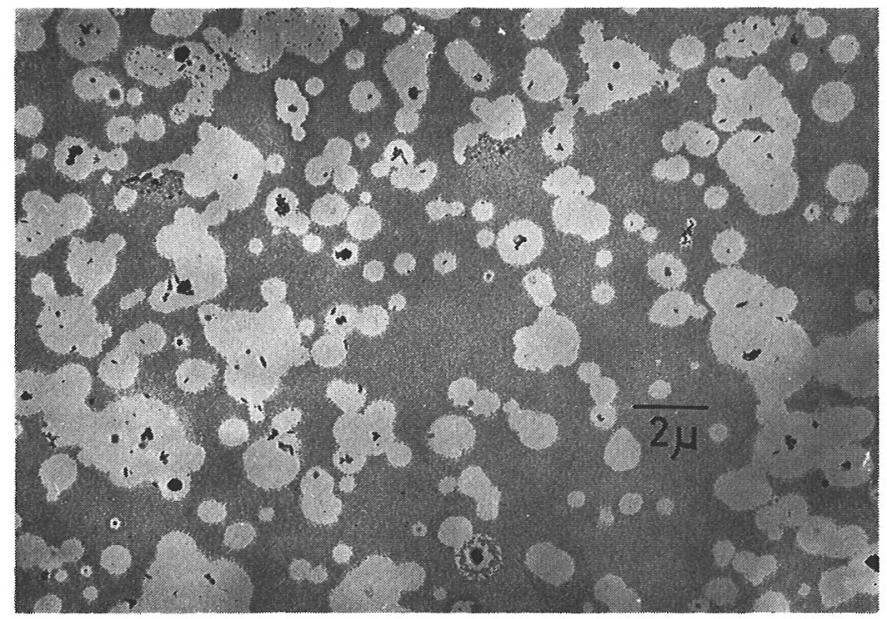

Fig. 12. Particles collected on copper film on 11 June 1972.

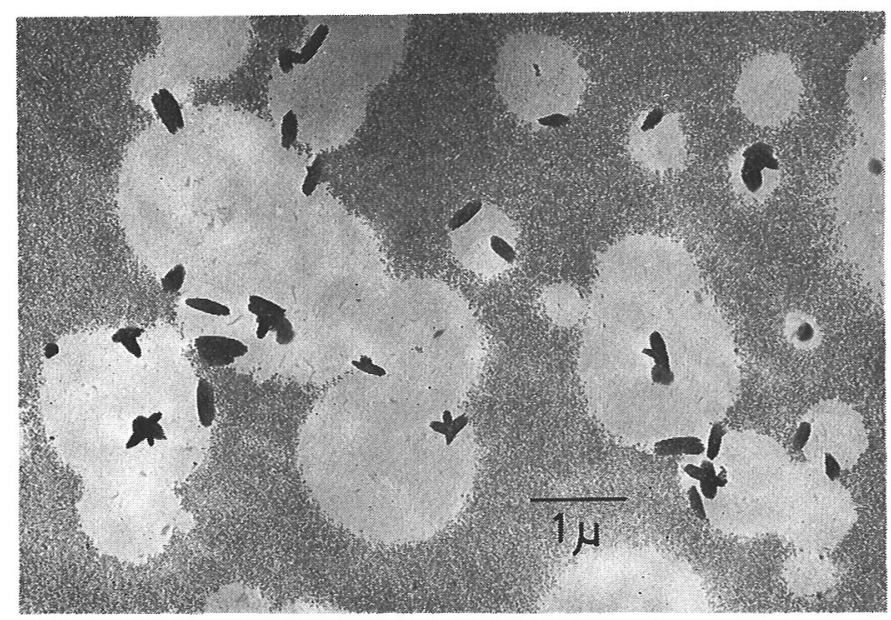

Fig. 13. Higher magnification of Fig. 12. 